

\title{
Epitaxial growth of tantalum carbides by low carbon flow carburizing
}

Dominique Cotton, Philippe Jacquet, Sébastien Faure, Vincent Vignal

\section{To cite this version:}

Dominique Cotton, Philippe Jacquet, Sébastien Faure, Vincent Vignal. Epitaxial growth of tantalum carbides by low carbon flow carburizing. Materials Chemistry and Physics, 2017, 192, pp.170-180. 10.1016/j.matchemphys.2016.12.063 . hal-01484824

\section{HAL Id: hal-01484824 \\ https://hal.science/hal-01484824}

Submitted on 7 Mar 2017

HAL is a multi-disciplinary open access archive for the deposit and dissemination of scientific research documents, whether they are published or not. The documents may come from teaching and research institutions in France or abroad, or from public or private research centers.
L'archive ouverte pluridisciplinaire $\mathbf{H A L}$, est destinée au dépôt et à la diffusion de documents scientifiques de niveau recherche, publiés ou non, émanant des établissements d'enseignement et de recherche français ou étrangers, des laboratoires publics ou privés. 


\title{
Epitaxial growth of tantalum carbides by low carbon flow carburizing
}

\author{
Dominique Cotton ${ }^{\text {a, b, c, * }}$, Philippe Jacquet ${ }^{\text {c, }}{ }^{\text {, }}$, Sébastien Faure ${ }^{\text {a }}$, Vincent Vignal ${ }^{b}$ \\ ${ }^{a}$ CEA, DAM, Valduc, 21100, Is-sur-Tille, France \\ b ICB, UMR 6303 CNRS - Université Bourgogne-Franche comté, BP 47870, 21078 Dijon Cedex, France \\ ${ }^{\mathrm{c}}$ Pôle Matériaux et Structures, Ecole Catholique des Arts et Métiers, 69005, Lyon, France \\ ${ }^{\mathrm{d}}$ LABOMAP, Arts et Métiers ParisTech, 71250, Cluny, France
}

\section{H I G H L I G H T S}

- Different kinds of carbides could appear on a tantalum sample if the carbon flux varies on its surface.

- Epitaxial relationships between $\mathrm{Ta}, \mathrm{Ta}_{2} \mathrm{C}$ and $\mathrm{TaC}$ are highlighted in tantalum carbide layers.

- Under specifics carbon flux, TaC carbide layer grow in relation with the Ta substrate.

- Columnar and equiaxed growths of carbide layers are separated by a carbon boundary flux.

o

\section{Keywords:}

Carbides

Multilayers

Coatings

Epitaxial growth

Electron diffraction

Diffusion

\begin{abstract}
A B S T R A C T
The carburizing of tantalum samples under different carbon flow rates has highlighted the influence of the carbon flow rate on the structure of tantalum carbides. XRD analyses enabled the identification of surface structures that were revealed by optical micrographs. Four carbon flow rates were tested. The

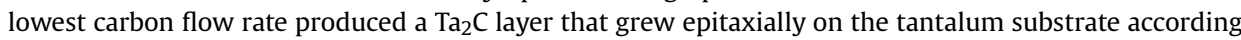
to the relationship: $\{10 \overline{1}\}_{\mathrm{Ta}} / /\{\overline{1} 101\}_{\mathrm{Ta} 2 C} ;\langle 10 \overline{1}\rangle_{\mathrm{Ta}} / /\langle\overline{1717010}\rangle_{\mathrm{Ta} 2 \mathrm{C} .}$. An increase in the carbon flow rate resulted in the appearance of $\mathrm{TaC}$ nuclei through the carbon enrichment of the $\mathrm{Ta}_{2} \mathrm{C}$ layer. These nuclei appeared in the form of islets and highly oriented needles. EBSD (Electron Back Scattered Diffraction) analyses and pole figures revealed that the carbide layers grew epitaxially towards their substrates. The $\mathrm{Ta}_{2} \mathrm{C}$ layer grew according to the relationship $\{10 \overline{1}\}_{\mathrm{Ta}} / /\{\overline{1} 101\}_{\mathrm{Ta} 2 \mathrm{C}}$ while the TaC structures nucleated according to the following relationships: $\{111\}_{\mathrm{TaC}} / /\{0001\}_{\mathrm{Ta} 2 \mathrm{C} ;}\langle 111\rangle_{\mathrm{TaC}} / /\langle 0001\rangle_{\mathrm{Ta} 2 \mathrm{C}} ;\{100\}_{\mathrm{TaC}} / /\{20 \overline{2} 3\}_{\mathrm{Ta} 2 \mathrm{C}}$; $\langle 100\rangle_{\mathrm{TaC}} / /\langle 90 \overline{9} 8\rangle_{\mathrm{Ta} 2 \mathrm{C}}$ and $\{110\}_{\mathrm{TaC}} / /\{10 \overline{1} 3\}_{\mathrm{Ta} 2 \mathrm{C}}\langle 110\rangle_{\mathrm{TaC}} / /\langle 90 \overline{9} 16\rangle_{\mathrm{Ta} 2 \mathrm{C}}$. The highest carbon flow produced stoichiometric $\mathrm{TaC}$ grains at the surface, which appeared to be equiaxed. The diversity of the TaC crystallographic orientations stems from the underlying $\mathrm{Ta}_{2} \mathrm{C}$ layer, the $\mathrm{TaC}$ grains having nucleated epitaxially from the $\mathrm{Ta}_{2} \mathrm{C}$ layer. This misorientation of the $\mathrm{Ta}_{2} \mathrm{C}$ grains with respect to $\mathrm{Ta}$ is governed by the exceeding of a carbon flow limit.
\end{abstract}

\section{Introduction}

Carburizing process increases the concentration of carbon at the surface of a metallic part. This increase in carbon concentration improves certain surface properties for a variety of applications: an increase in hardness for better contact conditions, the creation of a thermal barrier, the creation of a catalytic layer, etc. For example,

\footnotetext{
* Corresponding author. Current address: Arts et Métiers ParisTech, Rue Porte de Paris, 71250, Cluny, France.

E-mail addresses: dominique.cotton@ensam.eu (D. Cotton), philippe.jacquet@ ecam.fr (P. Jacquet), sebastien.faure@cea.fr (S. Faure), vincent.vignal@ubourgogne.fr (V. Vignal).
}

the tantalum carbide $\mathrm{TaC}$ is a compound that can be produced with a carburizing process. It is a compound of extreme hardness, which can exceed $5000 \mathrm{HK}[1]$. This property makes it the coating material of choice for cutting tool inserts [2]. This material has also been extensively studied for its refractory properties [3,4] on account of its high melting temperature of nearly $4270 \mathrm{~K}[5,6]$.

Some carburizing techniques for tantalum are described in the literature. The oldest procedure for tantalum carburizing uses solid carbon $[7,8]$, with temperatures higher than $2000{ }^{\circ} \mathrm{C}$. Other procedures use hydrocarbons as a carburizing gas, such as atmospheric carburizing [9] or low-pressure carburizing. The low pressure carburizing consist of injecting a carburizing gas such as $\mathrm{CO}, \mathrm{CO}_{2}$ or a hydrocarbon $\left(\mathrm{CH}_{4}, \mathrm{C}_{2} \mathrm{H}_{2}, \mathrm{C}_{2} \mathrm{H}_{4}, \mathrm{C}_{3} \mathrm{H}_{8}, \ldots\right)$ into the chamber 
[10-13]. This type of procedure can be complemented by the use of plasma $[14,15]$.

Tantalum carburizing gives rise to the appearance of two main carbides: TaC and $\mathrm{Ta}_{2} \mathrm{C}$ [16]. TaC is an FCC (Face Centered Cubic) compound ( $\mathrm{NaCl}$ - or B1-type structure) [6,16]. According to Lesser et al. [17], TaC can exist in a non-stoichiometric form, and can contain between 42.5 and 50 at.\% carbon. This variation in stoichiometry brings about changes in the lattice parameter [5,12,17-19], which can vary between 4.41 and $4.4545 \AA . \mathrm{Ta}_{2} \mathrm{C}$ has two allotropic phases, $\alpha-\mathrm{Ta}_{2} \mathrm{C}$ (ordered carbon sublattice, $\mathrm{CdI}_{2}$ antitype structure) and $\beta-\mathrm{Ta}_{2} \mathrm{C}$ (disordered carbon sublattice, $\mathrm{L}^{\prime} 3$ structure) $[6,20]$. The allotropic transformation between $\alpha$ - and $\beta$ $\mathrm{Ta}_{2} \mathrm{C}$ occurs at approximately $1950 \mathrm{~K}$ [21].

One of the more recent phase diagrams [21] describes two other tantalum carbides: $\mathrm{Ta}_{4} \mathrm{C}_{3}$ ( $\zeta$ phase) and $\mathrm{Ta}_{6} \mathrm{C}_{5}$. $\mathrm{Ta}_{4} \mathrm{C}_{3}$ was described for the first time by Lesser et al. [17]. It is a rhombohedral carbide ( $R 3 \mathrm{~m}$ space group) that appears in the presence of $\mathrm{TaC}$ and $\mathrm{Ta}_{2} \mathrm{C}$ $[17,22,23] . \mathrm{Ta}_{6} \mathrm{C}_{5}$ is an ordered phase created by the order-disorder transition of non-stoichiometric $\mathrm{TaC}_{\mathrm{x}}[24,25]$. These two carbides appear after long annealing times.

Many papers deal with the growth of tantalum carbide layers [7,22,26-31]. These papers describe carbide layers with thicknesses ranging from a few tens of microns to several hundred microns. These layers always have a two-phase structure, with $\mathrm{TaC}$ at the surface and $\mathrm{Ta}_{2} \mathrm{C}$ underneath $[26,28,29,32]$. Other papers $[7,27,30,31]$ report a three-phase structure with $\mathrm{Ta}_{4} \mathrm{C}_{3}$ interposed between $\mathrm{TaC}$ and $\mathrm{Ta}_{2} \mathrm{C}$ layers.

These layers were analyzed based on micrographs, XRD and XPS in order to identify the nature of the phases [32]. However, the crystallographic orientations of carbide layers produced by carburizing have not been addressed in the literature. Very few studies have dealt with the mechanisms of the development of tantalum carbide layers through tantalum carburizing. Based on the results obtained so far, the following mechanism has been proposed [32]:

- The first carbide layer that forms is $\mathrm{Ta}_{2} \mathrm{C}$. It is produced by the saturation of tantalum with carbon.

- Next, a layer of $\mathrm{TaC}$ develops through carbon enrichment of the $\mathrm{Ta}_{2} \mathrm{C}$ layer.

These hypotheses are based on micrographic observations of two-phase $\mathrm{TaC}+\mathrm{Ta}_{2} \mathrm{C}$ structures. Currently, no experimental confirmation of such a formation mechanism has been reported in the literature. The present study was conducted with the aim of observing the very first stages in the development of tantalum carbide layers. The nature of the carbide layers was determined by XRD. The crystallographic orientations of the various phases were studied by EBSD.

\section{Experimental procedure}

\subsection{Materials and tantalum carburizing}

During carburizing, tantalum becomes saturated with carbon very quickly, which results in the appearance and rapid growth of surface carbide layers [32]. To observe the very first stages in the development of these layers, the extent to which tantalum becomes saturated with carbon at the surface must be reduced. There are two ways of achieving this: increase the solubility of carbon in tantalum by increasing the temperature or decrease the carbon supply from carburizing.

According to the $\mathrm{Ta}-\mathrm{C}$ phase diagram [21], the solubility of tantalum can be increased to 7.5 at.\% by raising the carburizing temperature to $3015 \mathrm{~K}$. However, various technical problems prevent this temperature from being reached. Thus, limiting the carbon supply appears to be the easier option.

Samples measuring $5 \mathrm{~mm}$ thick and $14 \mathrm{~mm}$ in diameter were machined from a bar of tantalum (99.9\% purity). Carburizing tests were carried out in a thermochemical treatment furnace under reduced pressure. The carburizing procedure comprised of the following steps: creation of a vacuum in the chamber, heating, carburizing itself and finally, cooling. The pressure was reduced to less than 0.1 mbar. The carburizing temperature $\left(1600{ }^{\circ} \mathrm{C}\right)$ was attained with a heating rate of $30^{\circ} \mathrm{C} / \mathrm{min}$. The tantalum samples were then carburized by injecting 20 mbar of hydrogen into the chamber containing solid carbon. The gas was kept in the chamber for $5 \mathrm{~min}$, after which a primary vacuum was created and maintained for one hour. The samples were then cooled in $\mathrm{N}_{2}$ at a pressure of 1 bar.

The above procedure was chosen with the aim of reducing the carbon supply during carburizing. During time when the chamber was filled with hydrogen, the gas reacted with the solid carbon to form hydrocarbons. The vacuum created drastically reduced the partial pressure of the hydrocarbons, thereby reducing the rate of carburizing of tantalum.

The holder and the resistors are made of graphite. The holder is a possible source of carbon, but at $1600^{\circ} \mathrm{C}$, the carbon vapor pressure is too low to carburize tantalum [29]. A media gas, such as hydrogen, is needed to carry the carbon from the holder to the tantalum sample. Moreover, the holder side carburizing is not homogeneous. The carburizing is higher on the edge than in the centre. If the holder would have been a carbon source, the carburizing would have been homogeneous.

According to the bibliography, the carbon source is hydrocarbons which result from the reaction between hydrogen and graphite parts [33]. Between $1400{ }^{\circ} \mathrm{C}$ and $1600{ }^{\circ} \mathrm{C}$, thermodynamic reaction data between carbon and hydrogen $[34,35]$ show that the most abundant gases produced are methane, acetylene and ethylene, according to reactions (1) to (3). The production of the methyl radical $\mathrm{CH}_{3}$ is also noted (4).

$\mathrm{C}+2 \mathrm{H}_{2} \leftrightarrow \mathrm{CH}_{4}$

$2 \mathrm{C}+\mathrm{H}_{2} \leftrightarrow \mathrm{C}_{2} \mathrm{H}_{2}$

$2 \mathrm{C}+2 \mathrm{H}_{2} \leftrightarrow \mathrm{C}_{2} \mathrm{H}_{4}$

$\mathrm{C}+3 / 2 \mathrm{H}_{2} \leftrightarrow \mathrm{CH}_{3} \cdot$

These gases are known to carburize tantalum at temperatures used here $[11,14,15,36]$. The thermodynamic data are given for gas in equilibrium with carbon. This is not the case of carburizing, because the produced hydrocarbon gases gradually disappear by tantalum carburizing.

Hydrocarbons react with tantalum surface and let adsorbed carbon and gaseous hydrogen. The adsorbed carbon diffuses in tantalum. Hydrogen could react with graphite's holder to create hydrocarbons again. This reaction would lead to a homogeneous carburizing of the holder surface but this is not the case. Carbon might come from another mechanism. The carburizing reaction between hydrogen and graphite parts is not yet well understood in this furnace.

\subsection{Surface preparation}

The tantalum samples possessed two flat parallel faces. Before carburizing, these faces were mechanically polished. The final step is achieved with a $3-\mu \mathrm{m}$ diamond paste. During carburizing, the samples were placed on a graphite holder. For the remainder of this paper, the free face will be referred to as the 'chamber side' while 
the face that was in contact with the holder will be called the 'holder side'.

As the chamber side encountered a strong carbon flow, this led to the formation of tantalum carbide layers identical to those described in the literature. The carburizing technique that was used did not sufficiently reduce the carbon flow on the chamber side. Observing the very first instants of carbide layer formation requires a much lower carbon flow than that experienced by the chamber side. In addition to a special carburizing technique, it was necessary to introduce a means of containment to limit the carbonaceous gases' access to the tantalum and reduce the carbon flow effectively.

The surface roughness of the holder meant that there was a confined space between the sample and the holder. This provided us with an effective means of limiting the carbon flow rate. The structures that formed on the holder side enabled an investigation of the initial stages of the development of tantalum carbide layers. Therefore, only this side was studied. The microstructures showed in this paper were observed on a representative sample.

The structures produced by carburizing were left as is, they were not chemically etched. The samples were cross-sectioned in order to study these structures across the depth. These cross-sections were polished until a finishing step involving the use of colloidal silica. The cross-sections that were intended for EBSD analysis required an additional step (vibration polishing for $12 \mathrm{~h}$ ).

\subsection{Analysis of surface microstructures}

A series of optical micrographs was obtained for several locations from the centre to the edge of the surface. Top views of the structures were examined. An Olympus BX51M microscope was used for these analyses.

The cross-sections were studied by means of a Field Emission SEM (JEOL JSM 7600-F). The accelerating voltage of the electron beam was $20 \mathrm{kV}$. The crystallographic orientations of the surface structures and the tantalum substrate were studied through EBSD observations of the cross-sections, with the help of a TSL EDAX OIM $\mathrm{XM}$ detector coupled to the Field Emission SEM. The step size (distance between each point that was analyzed) was $25 \mathrm{~nm}$.

The microstructures that developed at the surface were identified by MicroXRD, with a Bruker D8 Discover device. This device is equipped with a cobalt anticathode $\left(\lambda_{\mathrm{K} \alpha .1}=1.7889 \AA\right)$ and a collimator that reduces the beam diameter from 2000 to $50 \mu \mathrm{m}$. The areas that were analyzed in this study measured $500 \mu \mathrm{m}$ in diameter.

\subsection{Processing of EBSD Data}

$\mathrm{Ta}_{2} \mathrm{C}$ has a trigonal L'3 structure. During EBSD analysis, this type of structure can result in ambiguous plane indexing because of its pseudosymmetry [37,38]. This is reflected in the raw crystallographic orientation data, which sometimes indicate two different orientations within the same grain (Fig. $1 \mathrm{a}$ and b). Such erroneous indexing can be corrected by using an appropriate technique to process the raw data. The pseudosymmetry relationship must be incorporated in the processing software. In this study, this relationship was determined as $60^{\circ}$ in the [0001] direction. The crystallographic orientations of the $\mathrm{Ta}_{2} \mathrm{C}$ grains were homogenized by incorporating this relationship (Fig. 1c).

A clean-up procedure was carried out after this pseudosymmetry correction. In this procedure, the minimum grain size was defined as 6 pixels and the selected tolerance angle was $5^{\circ}$.

\section{Experimental results}

\subsection{Top views of microstructures}

Carburized samples are exhibiting a concentric structure on the holder side (Fig. 2), comprising of four zones with different microstructures (Fig. 3).

Fig. 3a) shows a top-view micrograph of Zone 1 . It reveals a homogeneous surface with grain boundaries running across it. The surface is scattered with light patches. Fig. 3b) was taken in Zone 2. The surface is composed of oriented needles. Different regions of preferential orientations are visible in this micrograph. Each region appears to have its own preferential orientations, which are unrelated to one another.

The top-view micrograph of Zone 3 (Fig. 3c) shows a structure analogous to that of Zone 2 in other words, a surface comprising of oriented needles that form several regions of preferential orientations. However, the relief created by these needles seems to be much less distinct and much more homogeneous in Zone 3 than in Zone 2. Zone 4 (Fig. 3d) shows a completely different structure from the structures described earlier. It shows a surface of equiaxed grains with diameters in the micron range.

The diversity of the microstructures is the result of the variation in the associated carbon flow rate, which increases from the centre (Zone 1 ) to the edge of the surface (Zone 4 ). The next analyses were carried out in order to identify surface compounds and explain the orientations of certain microstructures.

\subsection{Study of Zone 1}

The XRD analysis of Zone 1 reveals the presence of two Ta peaks (JCPDS card 4-0788) that can be attributed to the underlying substrate. The analysis also shows that two compounds were detected: $\mathrm{Ta}_{2} \mathrm{C}$ (JCPDS card 32-1280) and C3Ta4 (JCPDS card 03-065-3191). The compound $\mathrm{C} 3 \mathrm{Ta} 4$ is described in the literature as having an $\mathrm{NaCl}$ structure of the [39] $P m \overline{3} m$ space group with a lattice parameter of $4.42 \AA$. This compound is in fact $\mathrm{TaC}_{0.75}$ and therefore an under-stoichiometric $\mathrm{TaC}\left(\mathrm{TaC}_{\mathrm{us}}\right) \cdot \mathrm{TaC}_{\mathrm{us}}$ must not be confused with the compound $\mathrm{Ta}_{4} \mathrm{C}_{3}$, which has a rhombohedral structure and belongs to the $R \overline{3} m[21,40,41]$ space group.

Fig. 4a) shows a cross-sectional view of the structures that developed on the surface of Zone 1; a carbide layer is visible on this surface. This layer is polycrystalline and mainly composed of a single layer of grains. The carbide layer is $431 \pm 82 \mathrm{~nm}$ thick and the grains are less than $500 \mathrm{~nm}$ wide. A precipitate located beneath the carbide layer is also visible. The parallel striations in this precipitate are indicative of significant twinning. Twinning in $\mathrm{Ta}_{2} \mathrm{C}$ precipitates has already been reported by Dahmen [42]. According to this author, twinning is a mechanism for accommodating the stresses that are induced during the cooling stage.

The phase map (Fig. 4b) shows that the surface layer was indexed as $\mathrm{Ta}_{2} \mathrm{C}$. As only a negligible amount of $\mathrm{TaC}_{\mathrm{us}}$ was indexed, this compound did not show up in the phase map.

The crystallographic orientation map (Fig. 4c) shows that the $\mathrm{Ta}_{2} \mathrm{C}$ layer is composed of grains having different orientations. There appear to be three orientations. As the high indices of these planes do not give a clear indication of the orientations, the latter have been plotted in an inverse pole figure (Fig. 5).

Fig. 4c) also shows that the analyzed zone only contains a single Ta grain. The preferential growth direction of the $\mathrm{Ta}_{2} \mathrm{C}$ layer and the small number of crystallographic orientations point to the existence of an epitaxial relationship between $\mathrm{Ta}$ and $\mathrm{Ta}_{2} \mathrm{C}$. Pole figures were plotted to explore the relationship between a $\mathrm{Ta}_{2} \mathrm{C}$ grain (Fig. 6b) and a Ta grain (Fig. 6a), as well as that between the entire $\mathrm{Ta}_{2} \mathrm{C}$ layer (Fig. 6d) and Ta (Fig. 6c). RD and TD stand for Rolling 

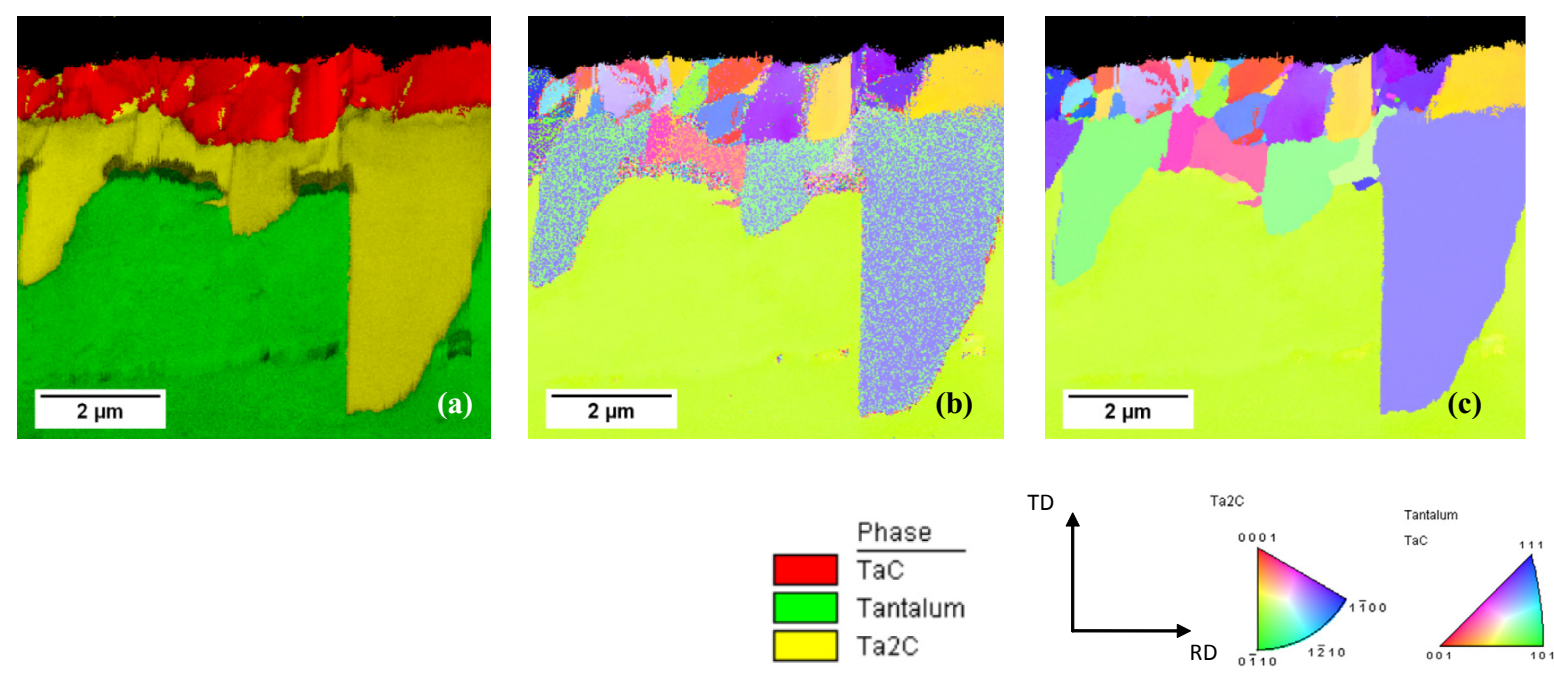

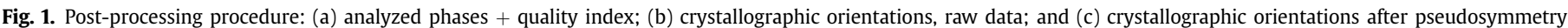
corrections.

Direction and Transverse Direction respectively. These directions constitute the axes of the pole figures. Only the positive hemispheres have been represented.

The pole figure for the comparison between a $\mathrm{Ta}_{2} \mathrm{C}$ grain (Fig. 6b) and a Ta grain (Fig. 6a) indicates an epitaxial relationship between two planes of the $\{10 \overline{1}\}$ family in Ta and two planes of the $\{1101\}$ family. Such a relationship was previously reported in the literature [42]. The $\{\overline{1} 101\}$ pole figure obtained for the $\mathrm{Ta}_{2} \mathrm{C}$ layer (Fig. $6 \mathrm{~d}$ ) shows that the $\mathrm{Ta}_{2} \mathrm{C}$ grains have other orientations besides those shown in Fig. 6c). Some of these are planes belonging to the $\{10 \overline{1}\}$ family in Ta. All the $\{10 \overline{1}\}$ planes of the pole figure match with the $\{\overline{1} 101\}$ planes in $\mathrm{Ta}_{2} \mathrm{C}$. This implies that the $\mathrm{Ta}_{2} \mathrm{C}$ grains possess several crystallographic orientations, but the epitaxial relationship is maintained and may apply to other $\{10 \overline{1}\}$ planes in Ta.

\subsection{Study of Zone 2}

The XRD analysis of Zone 2 indicates the presence of the same phases as those in Zone 1 , namely $\mathrm{Ta}_{2} \mathrm{C}$ and $\mathrm{TaC}_{\mathrm{us}}$. The Ta substrate was also detected. The results relating to Ta are comparable to those obtained for Zone 1 . As the $\mathrm{TaC}_{\mathrm{us}}$ peaks are all present in relation to JCPDS card 03-065-3191, the number of crystallographic orientations analyzed in the irradiated volume is higher than in Zone 1.

High-resolution micrography and EBSD analyses were carried out on cross-sections with the aim of explaining the preferential orientations of the surface microstructures.

The high-resolution SEM image (Fig. 7a) shows two phases at

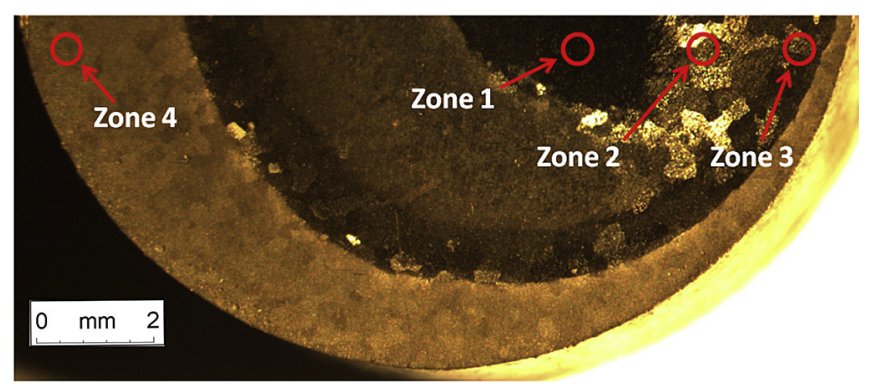

Fig. 2. Positions of the studied zones on the holder side. the surface, connected by an intermediate phase. The surface phase is discontinuous and forms a series of small bumps. These bumps are composed of alternating parallel bands which are characteristic of twinning. The bands all lie perpendicular to the surface. The EBSD analysis of Zone 2 (Fig. 7b and c) shows that the surface phase is composed of $\mathrm{TaC}$. The indexing software indexed the $\mathrm{TaC}_{\mathrm{us}}$ detected by XRD as stoichiometric TaC because of the small difference in lattice parameters $\left(\mathrm{TaC}_{\mathrm{us}}: 4.42 \AA\right.$ and $\mathrm{TaC}: 4.4545 \AA$ ). Most of the $\mathrm{TaC}$ grains have only two distinct orientations, which are shown in Fig. 8.

The second phase comprises highly elongated grains, the longest of which measure $8.5 \mu \mathrm{m}$ from the surface (Fig. 7a). Each surface bump is associated with an elongated grain. The EBSD analysis (Fig. 7b and c) shows that these grains are composed of $\mathrm{Ta}_{2} \mathrm{C}$. The layer is composed of several columnar grains of the same orientation.

The intermediate phase is a transitional phase between the surface phase and the elongated phase. This phase is lamellar and lies perpendicular to the surface. The lamellae are oriented in the same direction as the twin boundaries. The intermediate phase was not indexed by the EBSD analysis. The EBSD analyses concur with the XRD analysis on the nature of the surface phases.

Pole figures were plotted to study the possible crystallographic relationship between the Ta substrate and the $\mathrm{Ta}_{2} \mathrm{C}$ layer, as well as that between the $\mathrm{Ta}_{2} \mathrm{C}$ and $\mathrm{TaC}$ layers. Fig. $9 \mathrm{a}$ and b show the $\mathrm{Ta}$ $\{10 \overline{1}\}$ and $\mathrm{Ta}_{2} \mathrm{C}\{\overline{1} 101\}$ pole figures. Two $\{10 \overline{1}\}$ planes in Ta correspond to two $\{\overline{1} 101\}$ planes in $\mathrm{Ta}_{2} \mathrm{C}$ (Fig. 9b). This configuration is identical to that obtained in Zone 1.

The crystallographic relationships between $\mathrm{Ta}_{2} \mathrm{C}$ and $\mathrm{TaC}$ were also studied by means of pole figures (Fig. 9a and b). A comparison of the $\mathrm{TaC}\{111\}$ and $\mathrm{Ta}_{2} \mathrm{C}\{0001\}$ pole figures (Fig. 9c and $\mathrm{d}$ ) shows that:

- A plane from the $\{111\}$ family in TaC corresponds to $\{0001\}$ in $\mathrm{Ta}_{2} \mathrm{C}$.

- The TaC layer contains twins and the twin plane of $\mathrm{TaC}$ belongs to the $\{111\}$ family.

Indeed, the $\{111\}$ family possesses four equivalent planes. But the $\{111\}$ pole figure for TaC shows seven poles. Two distinct orientations may be observed in the pole figure. Therefore, there should be eight poles. However, two of the poles coincide because 

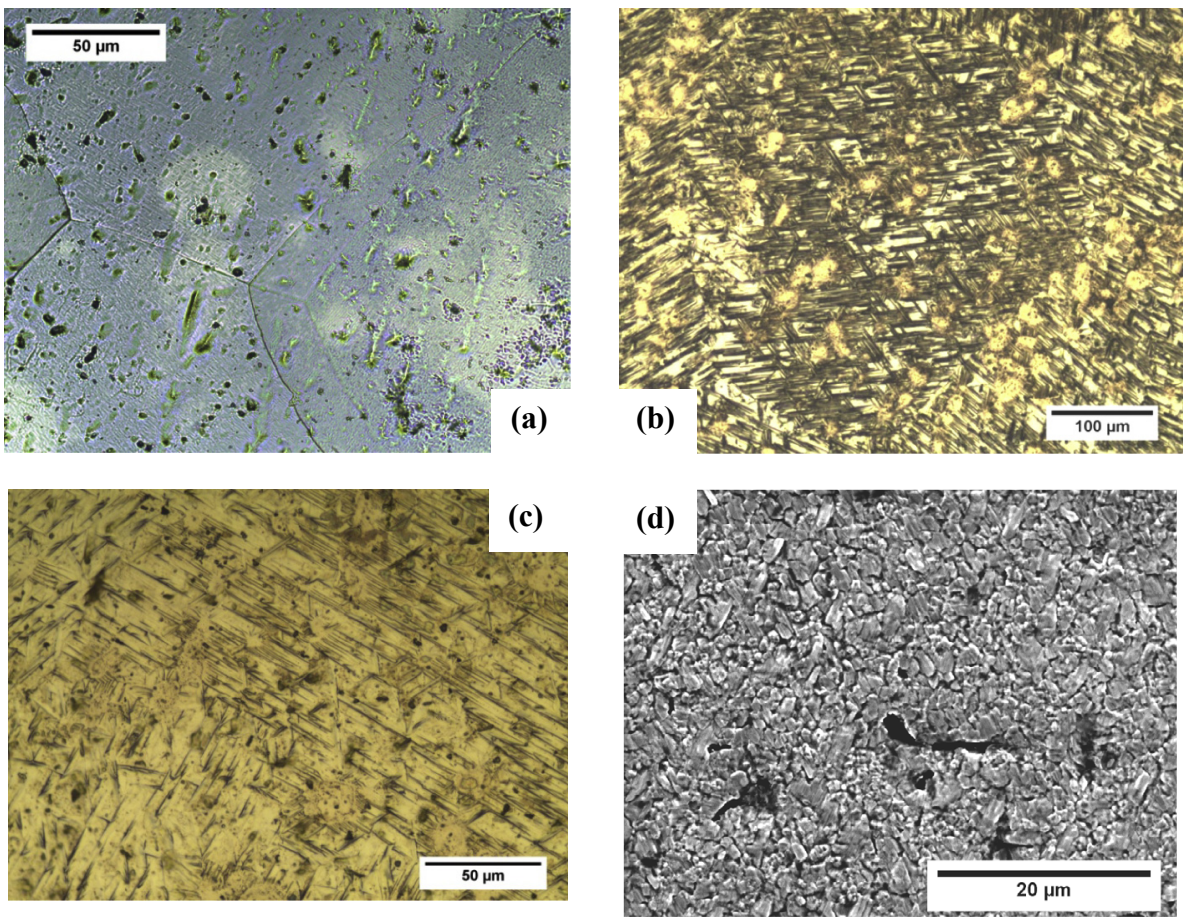

Fig. 3. Optical micrographs of zone 1 (a), zone 2 (b), zone 3 (c) and SEM micrograph of zone 4 (d).
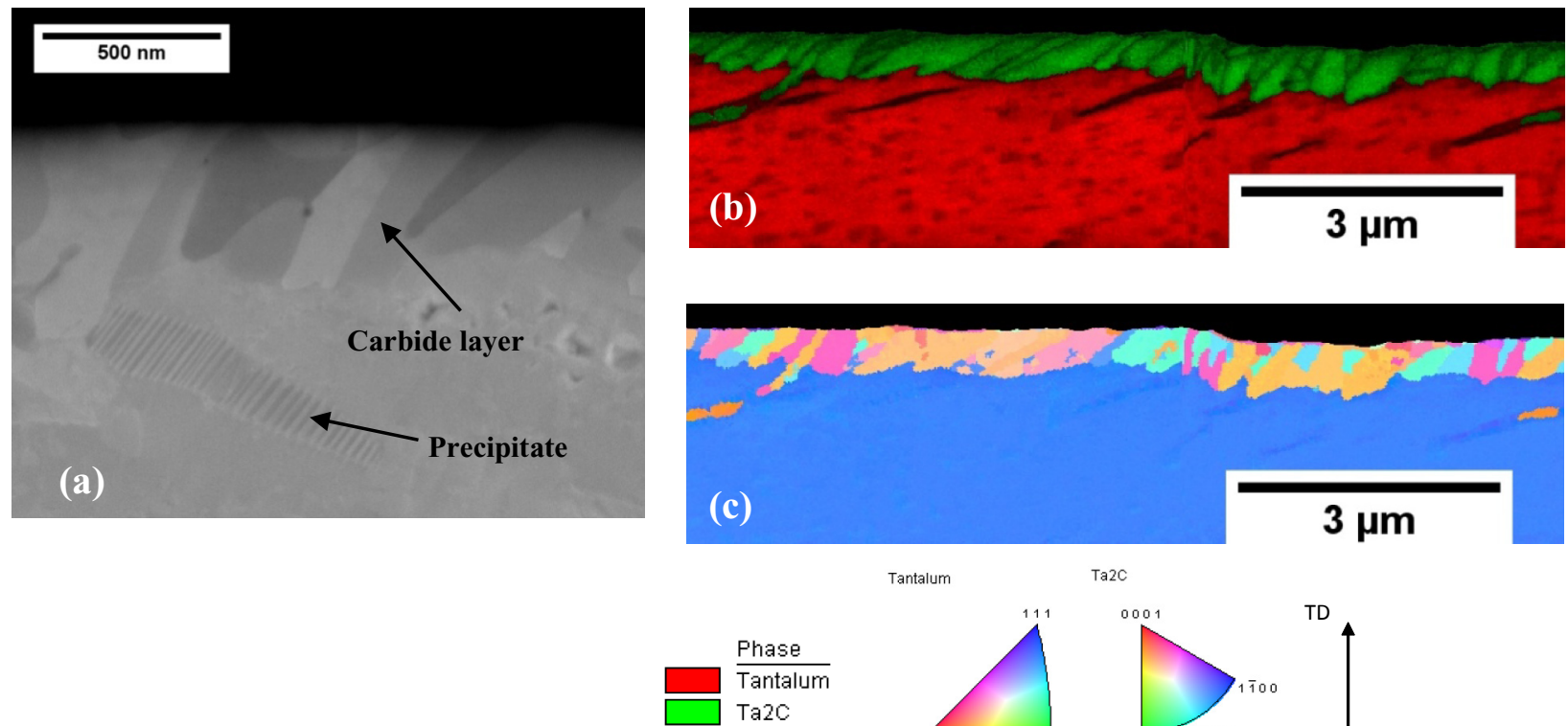

Tantalum

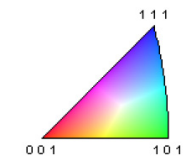

(1020
$\mathrm{Ta2C}$

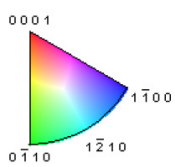

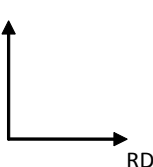

Fig. 4. (a) SEM micrograph of the cross-section of Zone 1 (backscattered electrons, $15 \mathrm{kV}$ ), (b) Phase + quality index map of the surface of Zone 1 and (c) IPF map of Zone 1.

the two orientations share a plane. This reduces the number of poles to seven.

Misorientation measurements were conducted between several twinned TaC grains. The measured angle was $60^{\circ} \pm 0.5^{\circ}$. This implies that the twinning in $\mathrm{TaC}$ consisted in a $60^{\circ}$ rotation about the [111] axis.

All the above observations can be explained by assuming that the intermediate phase is composed of $\mathrm{Ta}_{4} \mathrm{C}_{3}$. According to Rowcliffe [43] and Morris et al. [23], $\mathrm{Ta}_{4} \mathrm{C}_{3}$ could be an intermediate phase between $\mathrm{TaC}$ and $\mathrm{Ta}_{2} \mathrm{C}$. There is a crystallographic relationship between these three phases: $\{111\}_{\mathrm{TaC}} / /\{0001\}_{\mathrm{Ta} 4 \mathrm{C} 3} / /$ $\{0001\}_{\mathrm{Ta} 2 \mathrm{C}} ;\langle 110\rangle_{\mathrm{TaC}} / /\langle 10 \overline{10}\rangle_{\mathrm{Ta} 4 \mathrm{C} 3} / /\langle 10 \overline{10}\rangle_{\mathrm{Ta} 2 \mathrm{C}}$

This relationship accounts for why the TaC twin boundaries are aligned with the $\mathrm{Ta}_{4} \mathrm{C}_{3}$ laths (Fig. $7 \mathrm{a}$ ).

Thus, it appears that the strong orientation of the $\mathrm{TaC}$ needles results from the relationships between $\mathrm{TaC}$ and $\mathrm{Ta}_{2} \mathrm{C}$. There is also a relationship between the growth of $\mathrm{Ta}$ and $\mathrm{Ta}_{2} \mathrm{C}$. It is therefore likely that the orientation of the needles is directly linked to the 


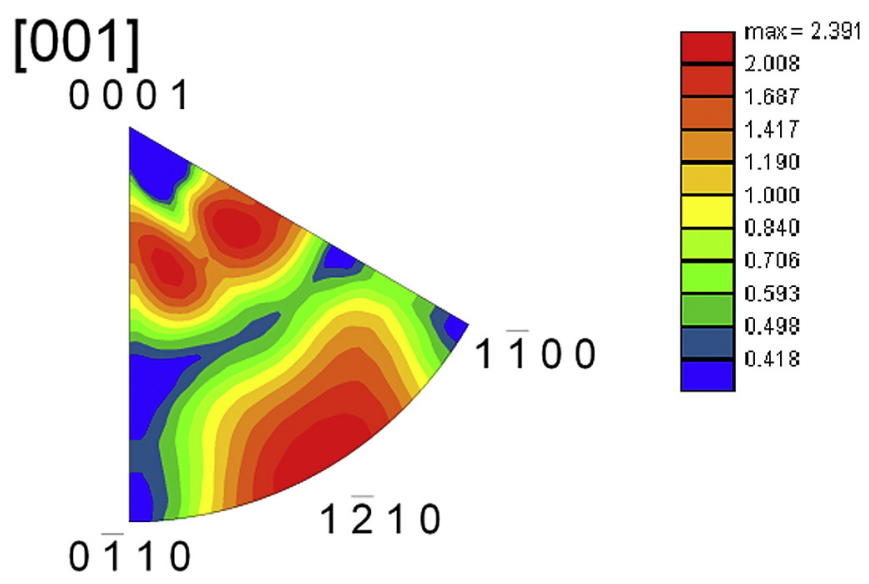

Fig. 5. [001] IPF showing the preferential orientations of the $\mathrm{Ta}_{2} \mathrm{C}$ layer in Zone 1 . extend into the underlying layer of grains. The EBSD analysis shows that this layer is composed of $\mathrm{Ta}_{2} \mathrm{C}$ (Fig. 10b). The orientation of the Ta substrate seems to be identical to that in Zone 2. It is possible that the EBSD analyses of Zones 2 and 3 were carried out in the same Ta grain. This would account for the similarities in the orientations within the TaC layer of these two zones.

The phase and quality index map (Fig. 10b) shows that the $\mathrm{Ta}_{2} \mathrm{C}$ layer is composed of grains having a columnar structure. The quality index map shows distinct grain boundaries in the $\mathrm{Ta}_{2} \mathrm{C}$ layer. However, the crystallographic orientation map (Fig. 10c) shows that the $\mathrm{Ta}_{2} \mathrm{C}$ layer is only composed of two grains that display pseudosymmetry relationship. The $\mathrm{Ta}_{2} \mathrm{C}$ grain boundaries shown in Fig. 10b) are not visible in the crystallographic orientation map. This is due to the pseudosymmetry correction procedure applied to $\mathrm{Ta}_{2} \mathrm{C}$. The raw data indicate the existence of a low level of misorientation between the various $\mathrm{Ta}_{2} \mathrm{C}$ grains. The misorientation was measured between 0 and $8^{\circ}$, which suffices to account for the (a)
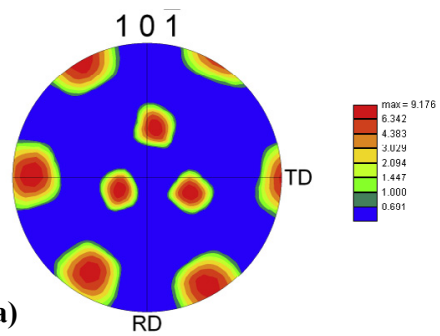

(c)

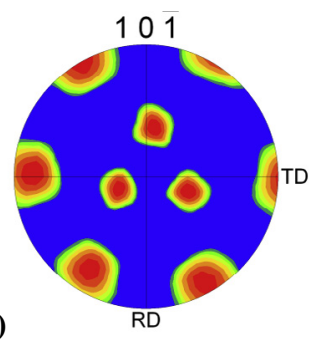

(b)

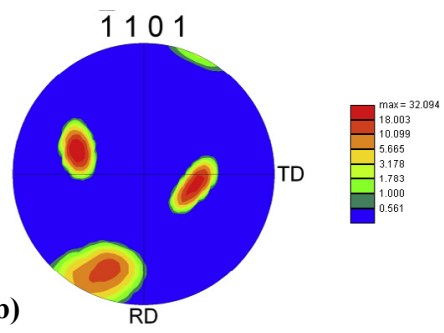

(d)

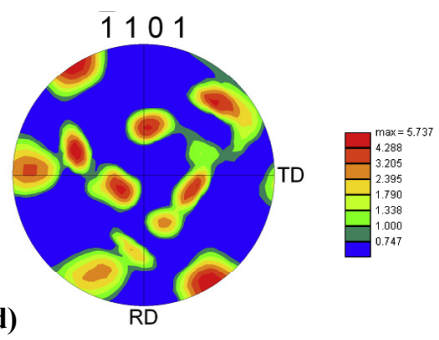

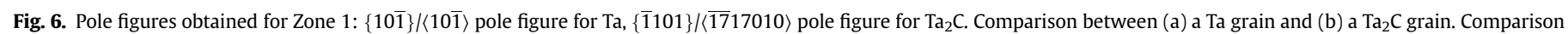
between (c) a Ta grain and (d) the entire $\mathrm{Ta}_{2} \mathrm{C}$ layer.

orientation of the Ta grains that make up the substrate of the carbide layers. This accounts for the texture followed by the needle growth Fig. 3b).

An examination of the pole figures also reveals twinning in the $\mathrm{TaC}$ layer by a $60^{\circ}$ rotation about the $\langle 111\rangle$ axis. This relationship can explain the star-shaped structures formed by the $\mathrm{TaC}$ needles, as seen in Zone 2 (Fig. 3b).

\subsection{Study of Zone 3}

The XRD analysis of Zone 3 indicates the presence of the same phases as those in Zones 1 and 2, namely $\mathrm{Ta}_{2} \mathrm{C}$ and $\mathrm{TaC}_{\mathrm{us}}$. The highresolution (cross-sectional) micrograph of Zone 3 Fig. 10a) shows a two-layer structure composed of two distinct phases connected by an intermediate lamellar phase. The surface phase is composed of columnar grains. The EBSD analysis of Zone 3 (Fig. 10b) shows that the surface phase is composed of TaC. This layer is thicker than that measured in Zone 2 (thickness of less than $2 \mu \mathrm{m}$ ). The TaC layer (Fig. 10b) is composed of columnar grains with two distinct orientations. These two orientations seem to be identical to those in Zone 2. The second layer of grains underlying the TaC layer is composed of columnar grains. The grain boundaries of the TaC layer presence of grain boundaries in the quality index map. This misorientation was eliminated by the pseudosymmetry correction.

Pole figures for Zone 3 show the same results than zone 2. The epitaxial relationship between $\mathrm{Ta}\{10 \overline{1}\}$ and $\mathrm{Ta}_{2} \mathrm{C}\{\overline{1} 101\}$ and between $\mathrm{TaC}\{111\}$ and $\mathrm{Ta}_{2} \mathrm{C}\{0001\}$ was verified.

\subsection{Study of Zone 4}

A XRD analysis of Zone 4 was obtained for the area containing the highest amount of carbon. The analysis show the appearance of a 'new' phase, stoichiometric TaC (JCPDS card 35-0801). This 'new' phase can be attributed to an enrichment of $\mathrm{TaC}_{\mathrm{us}}$ with carbon, causing an increase in the lattice parameter [6] and a shift in the peaks towards smaller angles.

Fig. 11a) shows a cross-sectional view of the surface structure in Zone 4. The layer that is visible in this micrograph comprises two layers of grains. The EBSD analysis (Fig. 11b) shows that these correspond to a $\mathrm{TaC}$ surface layer and an underlying $\mathrm{Ta}_{2} \mathrm{C}$ layer. The nature of the phases is identical to those identified in Zones 2 and 3. However, the EBSD analysis of Zone 4 reveals a visible change in the microstructure of the surface layers with respect to the layers in Zones 2 and 3 . While the phase and quality index map only shows a 

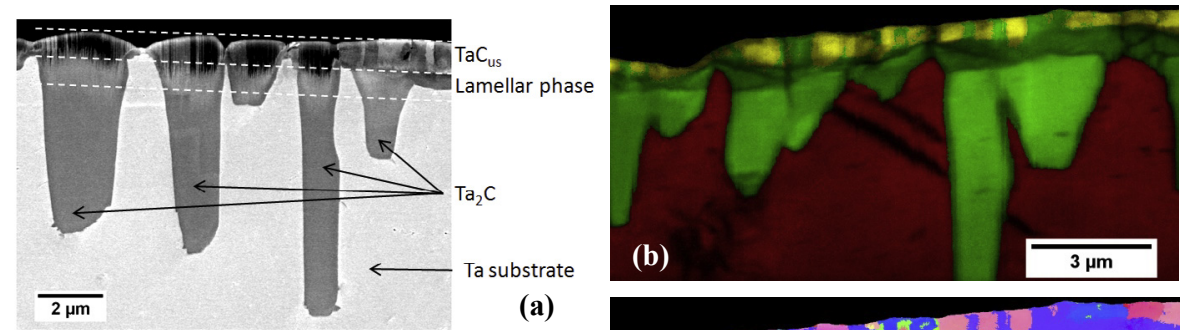

(a)
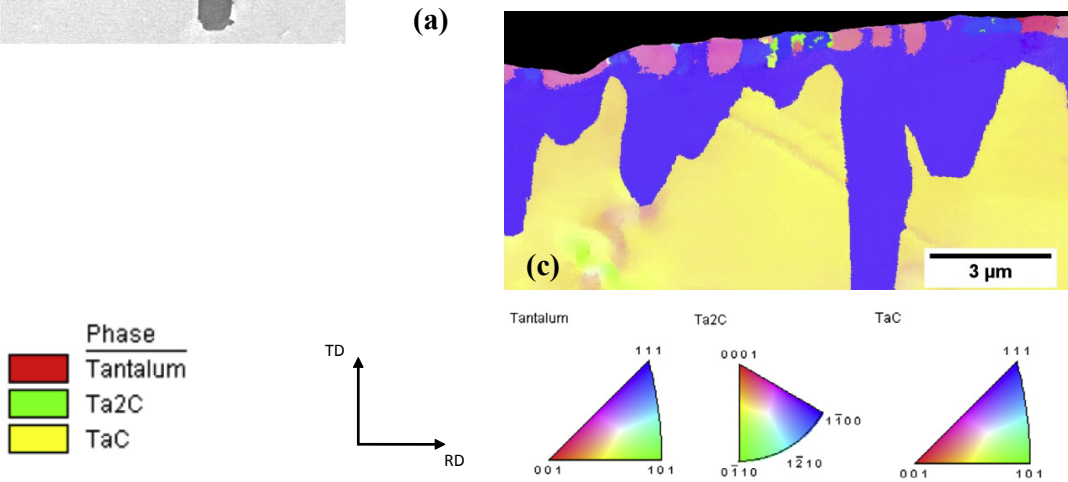

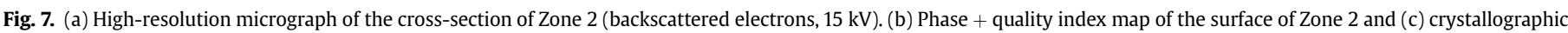
orientation map of Zone 2.

\section{[001]}

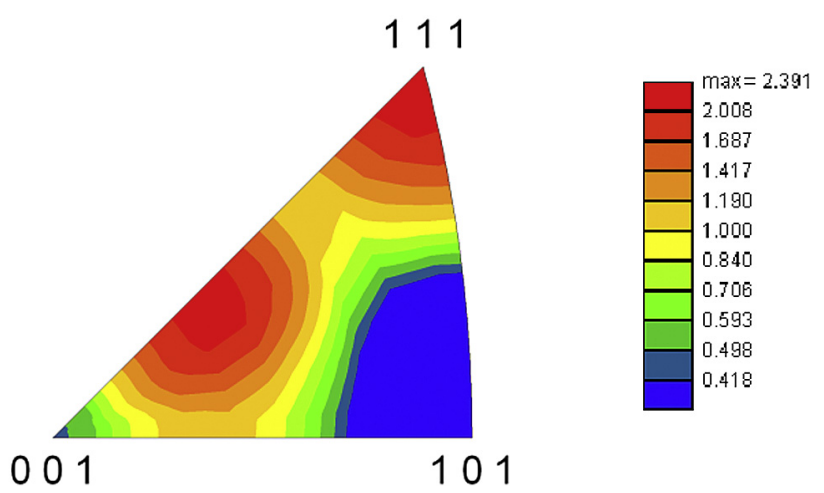

Fig. 8. [001] IPF showing the preferential orientations of the TaC layer in Zone 2.

thickening of the $\mathrm{TaC}$ layer at the expense of the $\mathrm{Ta}_{2} \mathrm{C}$ layer (Fig. 11b), the crystallographic orientation map (Fig. 11c) indicates a real change in the orientations of the two layers. The $\mathrm{TaC}$ and $\mathrm{Ta}_{2} \mathrm{C}$ layers possess a much wider range of crystallographic orientations.

However, it is important to note that Fig. 11b) shows the columnar structure of the two carbide layers and a continuity between the $\mathrm{TaC}$ and $\mathrm{Ta}_{2} \mathrm{C}$ grain boundaries. Also, there are only a few grain boundaries between the $\mathrm{TaC}$ and $\mathrm{Ta}_{2} \mathrm{C}$ layers. This may be attributed to the presence of the intermediate phase that is visible in Fig. 11a). This intermediate phase was not indexed.

The Ta $\{10 \overline{1}\}$ pole figure (Fig. 12a) and the $\operatorname{Ta}_{2} \mathrm{C}\{\overline{1} 101\}$ pole figure (Fig. 12b) confirm the diversification of the crystallographic orientations of $\mathrm{Ta}_{2} \mathrm{C}$. There is much more mismatch between the Ta and $\mathrm{Ta}_{2} \mathrm{C}$ poles.

The $\mathrm{TaC}\{111\}$ pole figure (Fig. $12 \mathrm{c}$ ) and the $\mathrm{Ta}_{2} \mathrm{C}\{0001\}$ pole figure show that the $\mathrm{TaC}$ and $\mathrm{Ta}_{2} \mathrm{C}$ poles still match, which proves that there are still certain crystallographic relationships between these two phases.

In order to verify this, other pole figures were plotted for areas including a $\mathrm{TaC}$ grain (Fig. 13a) and an adjacent $\mathrm{Ta}_{2} \mathrm{C}$ grain (Fig. 13b).
The pole figures show that both $\mathrm{TaC}$ grains experienced slight twinning. They also prove the existence of a relationship between the $\{0001\}$ plane in $\mathrm{Ta}_{2} \mathrm{C}$ and one of the $\{111\}$ planes in $\mathrm{TaC}$.

It appears that the crystallographic relationships between $\mathrm{Ta}$ and $\mathrm{Ta}_{2} \mathrm{C}$ in Zone 4 are not as strong as those in the other zones. But the relationships between $\mathrm{TaC}$ and $\mathrm{Ta}_{2} \mathrm{C}$ still exist.

The diversity of the crystallographic orientations of the TaC layer can account for the homogeneous and equiaxed microstructure that is visible in the surface micrograph (Fig. 3d).

\section{Discussion}

\subsection{Cross-sectional views of microstructures}

The carbon flux provided by the containment technique is not well defined. However, the flux is clearly reduced in the holder side compared to the chamber side. Optical micrographs were carried out on both sides (Fig. 14). They show that the $\mathrm{Ta}_{2} \mathrm{C}$ layer is thinner in holder side than in chamber side. However, carbide layers seem to be thicker in holder side (zone 5, Fig. 14b) than in chamber side (Fig. 14c). But the TaC layer is thicker in chamber side. Therefore, carbide layers in holder side contain less carbon despite they seem thicker.

The increase in carbon flow from the centre (Zone 1) to the edge (Zone 4) of the sample resulted in the progressive carbon enrichment of the surface. The small amount of $\mathrm{TaC}_{\text {us }}$ detected in Zone 1 increased in Zones 2 and 3, and even more so in Zone 4. It also became enriched with carbon and eventually turned into stoichiometric $\mathrm{TaC}$. This variation in the nature of the surface tantalum carbide can be explained by the degree to which the tantalum became saturated with carbon. The thinnest carbide layer $(431 \pm 82 \mathrm{~nm})$ was found in Zone 1 . This layer was composed of $\mathrm{Ta}_{2} \mathrm{C}$, the carbide having the lowest carbon content in the $\mathrm{Ta}-\mathrm{C}$ system [16]. This indicates that the carbon inflow was barely greater than the carbon diffusion rate close to the tantalum surface. The carbon flow rate was just sufficient to saturate the tantalum surface with carbon and thus create the $\mathrm{Ta}_{2} \mathrm{C}$ layer. The increase in the carbon flow in Zone 2 accelerated the growth of the $\mathrm{Ta}_{2} \mathrm{C}$ grains, leading to the appearance of highly elongated grains in the Ta 

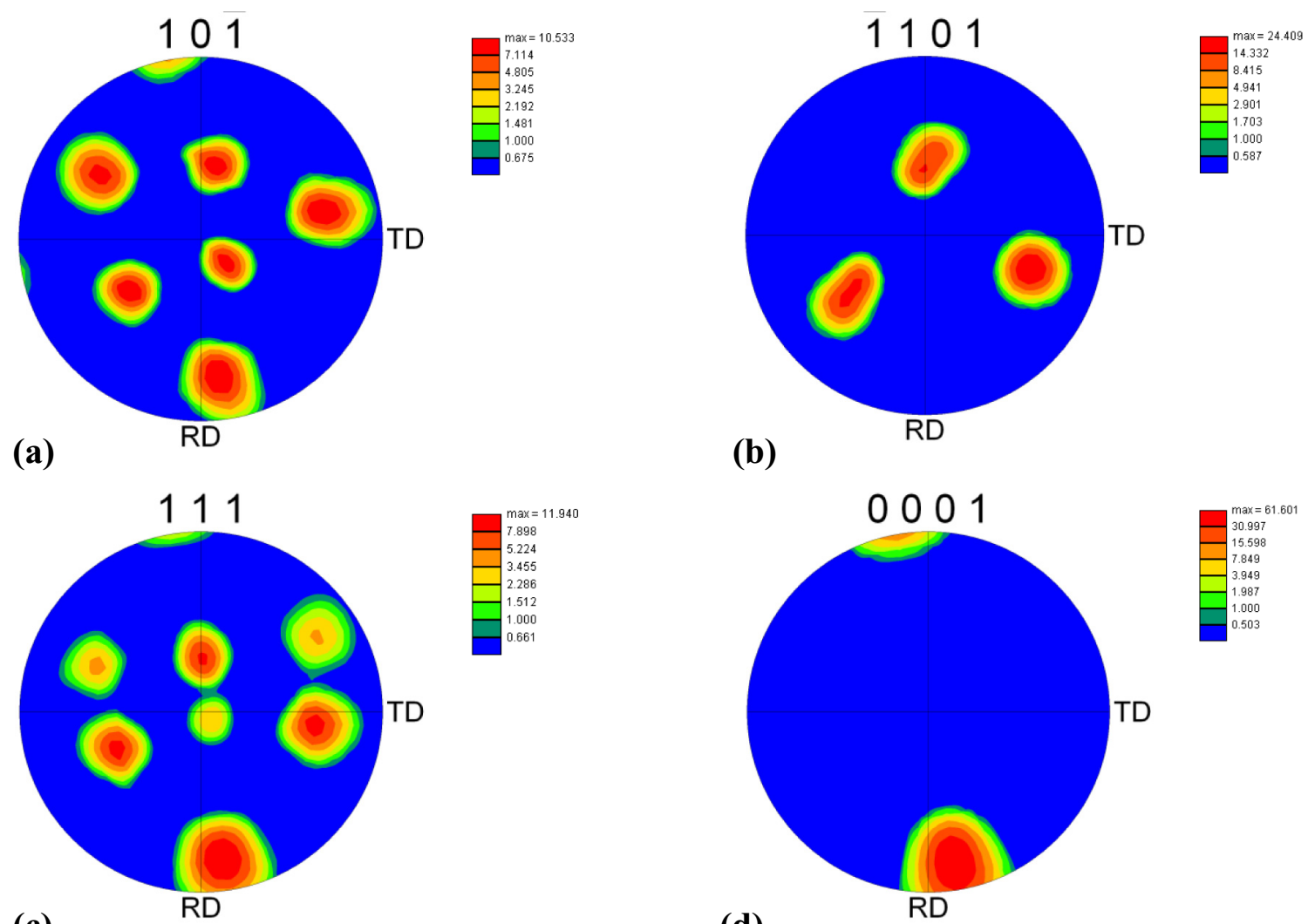

(c)

(b)

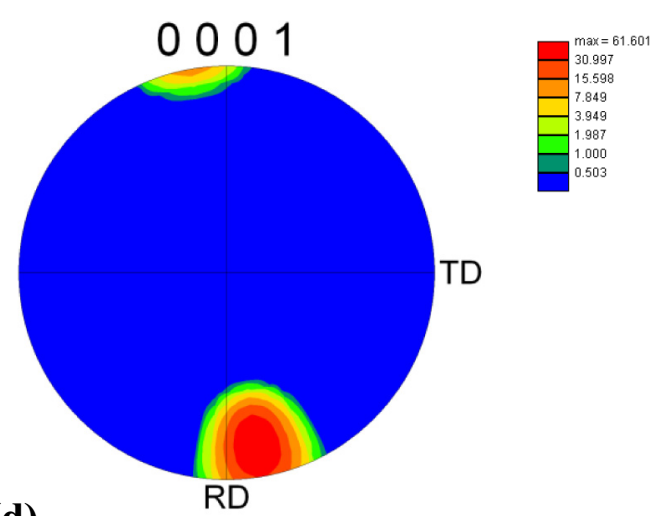

Fig. 9. Pole figures obtained for Zone 2. (a) $\{10 \overline{1}\} /\langle 10 \overline{1}\rangle$ pole figure for Ta, (b) $\{\overline{1} 101\} /\langle\overline{17} 17010\rangle$ pole figure for Ta 2 , (c) $\{111\} /\langle 111\rangle$ pole figure for TaC and (d) $\{0001\} /\langle 0001\rangle$ pole figure for $\mathrm{Ta}_{2} \mathrm{C}$.
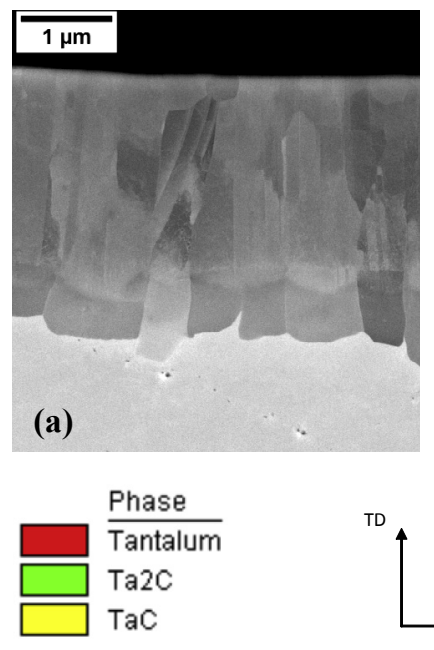

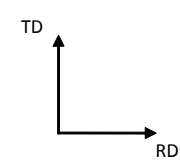

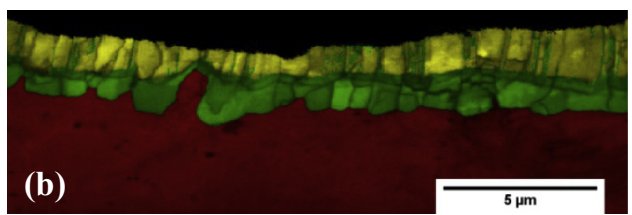
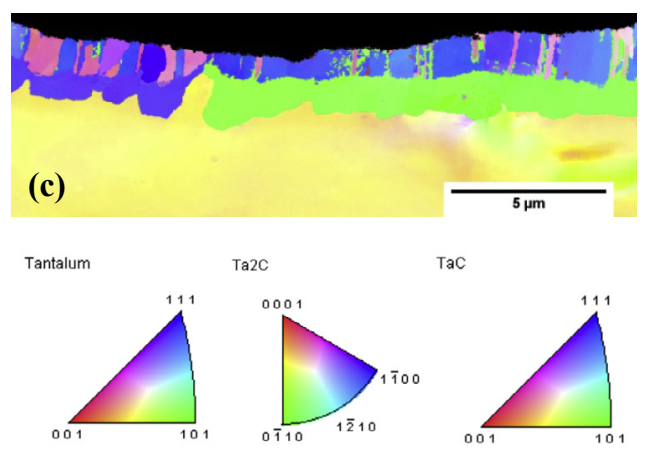

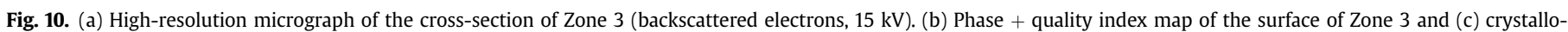
graphic orientation map of Zone 3.

substrate. The carbon flow rate was also sufficient to saturate the $\mathrm{Ta}_{2} \mathrm{C}$ layer with carbon, leading to the appearance of $\mathrm{TaC}$ on the surface. To our knowledge, the highly irregular growth of $\mathrm{Ta}_{2} \mathrm{C}$ grains has not been accounted for in the literature. It is possible that this exaggerated growth is due to a specific crystallographic orientation of $\mathrm{Ta}_{2} \mathrm{C}$. An examination of the $(0001) /\langle 0001\rangle$ pole figure for $\mathrm{Ta}_{2} \mathrm{C}$ (Fig. 9d) shows that the (0001) planes in the $\mathrm{Ta}_{2} \mathrm{C}$ grains are almost perpendicular to the surface, along the axis of grain growth. Meanwhile, Dahmen [42] has affirmed on his studies involving the precipitation of $\mathrm{Ta}_{2} \mathrm{C}$ in a Ta matrix that the favoured direction of growth of $\mathrm{Ta}_{2} \mathrm{C}$ precipitates is parallel to the (0001) planes. Thus, there is likely to be a connection between the crystallographic orientation of the $\mathrm{Ta}_{2} \mathrm{C}$ grains and their exaggerated growth (in comparison with the other zones). This hypothesis still needs to be confirmed. Compared with Zones 1 and 2, the increased carbon flow in Zone 3 led to an earlier appearance of the TaC layer. 

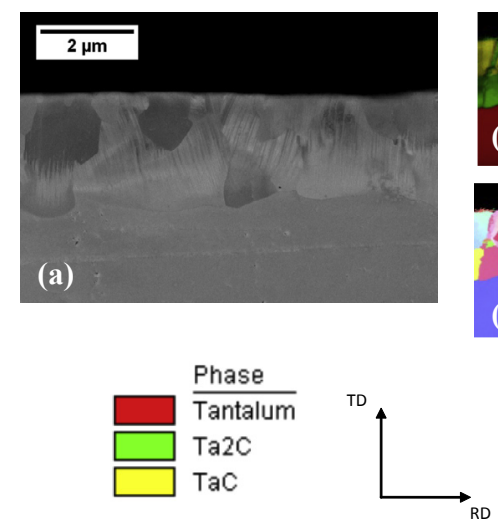
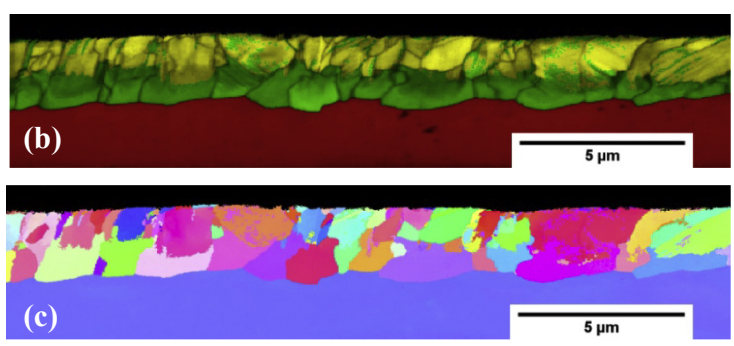

Tantalum

$\mathrm{Ta} 2 \mathrm{C}$

TaC
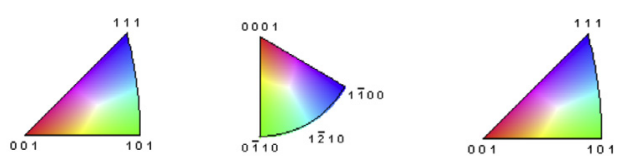

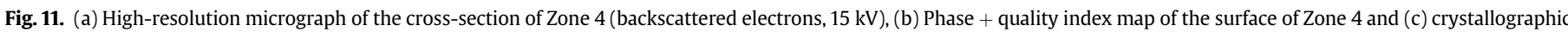
orientation map of Zone 4

At $1600{ }^{\circ} \mathrm{C}$, the diffusion coefficient of carbon was lower in the $\mathrm{TaC}$ layer than in the $\mathrm{Ta}_{2} \mathrm{C}$ layer $[7,26]$. The TaC layer acted therefore as a diffusion barrier against carbon, thereby hindering the growth of the $\mathrm{Ta}_{2} \mathrm{C}$ layer.

The carbon flow rate seems to govern the growth mode of the tantalum carbide layers. The columnar and oriented growth of the $\mathrm{TaC}$ and $\mathrm{Ta}_{2} \mathrm{C}$ grains in Zones 2 and 3 is much less visible in Zone 4, which experienced the highest carbon flow. The crystallographic orientation map of Zone 4 (Fig. 11c) shows a wide range of crystallographic orientations in the $\mathrm{Ta}_{2} \mathrm{C}$ layer, which is confirmed by the pole figures for $\mathrm{Ta}$ and $\mathrm{Ta}_{2} \mathrm{C}$. The crystallographic relationships between $\mathrm{TaC}$ and $\mathrm{Ta}_{2} \mathrm{C}$ are nonetheless maintained. There appears to be a carbon flow 'limit', beyond which the columnar growth of carbide grains is altered or even eliminated.

\subsection{Top views of microstructures}

The top views of the surface microstructures also vary with the

(a)

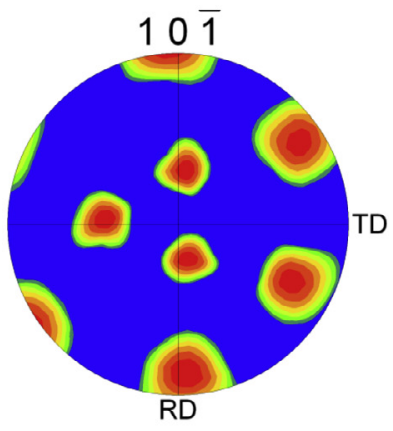

(c)

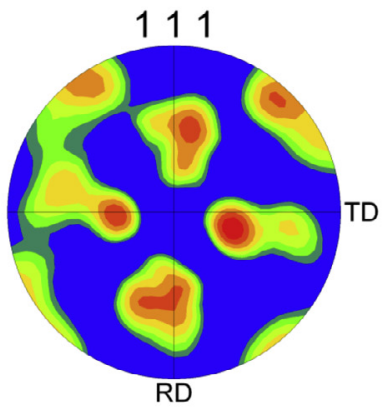

carbon flow. The top-view surface microstructure of Zone 2 (Fig. 3b) is composed of $\mathrm{TaC}$ needles and islets. The nature of the surface phase was determined through EBSD analyses. The influence of the carbon supply rate on the morphology of the surface microstructure has been addressed in the literature. Xiong et al. published a study on the epitaxial growth of $\mathrm{TaC}$ on graphite by CVD deposition [44]. They show that the rate of $\mathrm{TaC}$ deposition greatly influences the morphology of the carbide layer, which varies between a columnar and pyramidal structure at low deposition rates and a cauliflower structure at higher deposition rates. The present study points a carburizing stage which comprised two steps: carbon enrichment of the atmosphere (with a hydrogen + solid carbon combination), followed by dilution of the carbonaceous atmosphere by means of a primary vacuum. The supply of carbon to the tantalum therefore decreased when the vacuum was produced, during the carburizing stage. The presence of two different structures (islets and needles) composed of $\mathrm{TaC}$ within the same zone can therefore be attributed to the variation in the carbon flow (b)

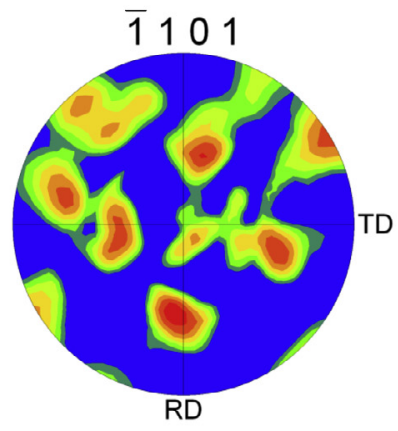

(d)

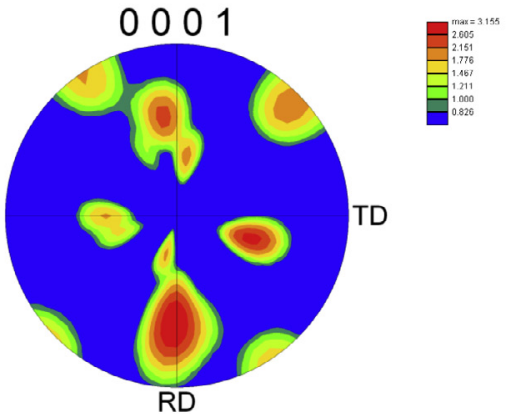

Fig. 12. Pole figures obtained for Zone 4. (a) $\{10 \overline{1}\} /\langle 10 \overline{1}\rangle$ pole figure for Ta, (b) $\{\overline{1} 101\} /\langle\overline{17} 17010\rangle$ pole figure for $\mathrm{Ta}_{2} \mathrm{C}$, (c) $\{111\} /\langle 111\rangle$ pole figure for TaC and (d) $\{0001\} /\langle 0001\rangle$ pole figure for $\mathrm{Ta}_{2} \mathrm{C}$. 

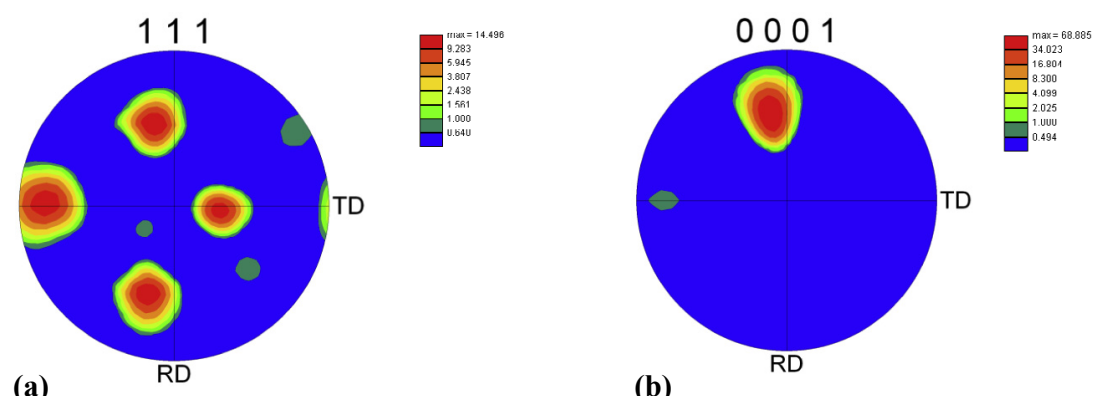

Fig. 13. Pole figures obtained for adjacent $\mathrm{TaC}$ and $\mathrm{Ta}_{2} \mathrm{C}$ grains, (a) $\{111\}$ pole figure for the $\mathrm{TaC}$ grain, (b) $\{0001\}$ pole figure for the Ta ${ }_{2} \mathrm{C}$ grain.
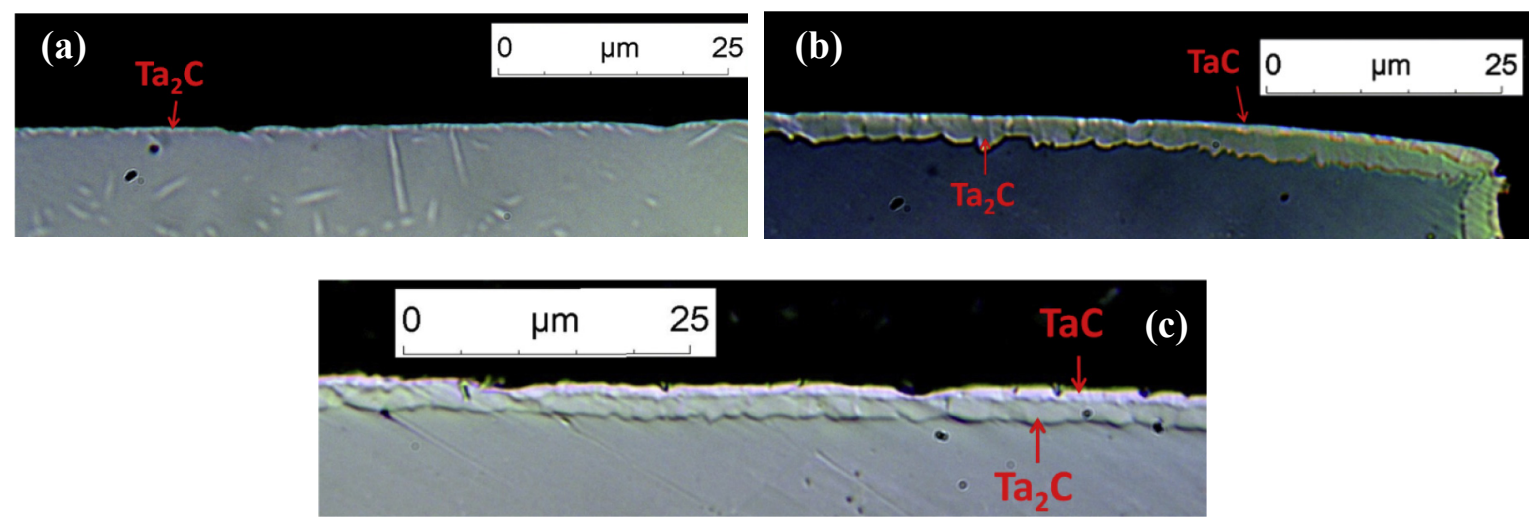

Fig. 14. (a) Optical micrograph of the holder side in zone 1, (b) in zone 5, (c) chamber side.

during the carburizing treatment.

The idea of a flow limit mentioned in the preceding paragraph becomes much clearer when the top views of Zones 2 and 3 (Fig. 3b and c) and Zone 4 (Fig. 3d) are compared. The strong texture of Zones 2 and 3 is replaced by an equiaxed microstructure in Zone 4 .

\section{Conclusions}

The carburizing of a tantalum sample under different carbon flow rates has highlighted the influence of the carbon flow rate on the surface microstructures.

A global analysis of the EBSD results has led to several conclusions. The first conclusion is that for a certain carbon flow rate, various tantalum carbide layers may grow epitaxially on the Ta substrate. Tantalum is related to $\mathrm{Ta}_{2} \mathrm{C}$ by the following crystallographic relationship: Ta $\{10 \overline{1}\} \quad / / \mathrm{Ta}_{2} \mathrm{C} \quad\{\overline{1} 101\} ;\langle 10 \overline{1}\rangle_{\mathrm{Ta}} / /$ $\langle\overline{1717010}\rangle_{\mathrm{Ta} 2 \mathrm{C}}$. The TaC layer is connected to the $\mathrm{Ta}_{2} \mathrm{C}$ layer by a third intermediate $\mathrm{Ta}_{4} \mathrm{C}_{3}$ phase. The relationship between $\mathrm{TaC}$ and $\mathrm{Ta}_{2} \mathrm{C}[1,23]$ has been verified through the use of pole figures. This relationship is as follows: $\{111\}_{\mathrm{TaC}} / /\{0001\}_{\mathrm{Ta} 4 \mathrm{C} 3} / /\{0001\}_{\mathrm{Ta} 2 \mathrm{C}}$; $\langle 110\rangle_{\mathrm{TaC}} / /\langle 10 \overline{10}\rangle_{\mathrm{Ta} 4 \mathrm{C} 3} / /\langle 10 \overline{10}\rangle_{\mathrm{Ta} 2 \mathrm{C}}$. The very strong texture of the microstructure in Zones 2 and 3 is the result of these crystallographic relationships.

The second conclusion is that beyond a certain carbon flow limit, the columnar and textured growth of the carbide layers is halted. Below this carbon flow limit, the carbide layer growth is columnar and highly textured because of the strong crystallographic relationships between the various phases. Exceeding the carbon flow limit has a strong impact on the morphology of the $\mathrm{TaC}$ layer. The grains are much more equiaxed and the development of oriented microstructures at the surface is interrupted. The crystallographic relationships between $\mathrm{TaC}$ and $\mathrm{Ta}_{2} \mathrm{C}$ are nonetheless maintained, but those between $\mathrm{Ta}$ and $\mathrm{Ta}_{2} \mathrm{C}$ are not as clear-cut. The actual value of the carbon flow limit has not been obtained. Determining this value would require flow calculations that are difficult to perform analytically.

It is interesting to note that epitaxial surface structures on substrates are generally obtained through CVD [44], PVD [45] or PLD [46]. It is therefore possible to obtain epitaxial tantalum carbides on substrates by low-pressure carburizing, with a device that limits the carbon flow towards the tantalum.

\section{Acknowledgements}

The authors are most grateful to the CEA and the Regional Council of Burgundy for their financial support. They also would like to thank Frédéric Herbst and Nicolas Geoffroy, engineers at the Laboratoire Interdisciplinaire Carnot de Bourgogne (UMR 6303 CNRS, Université de Bourgogne, Dijon, France), for their assistance in the acquisition and understanding of the EBSD and XRD data.

\section{References}

[1] D.J. Rowcliffe, W.J. Warren, Structure and properties of tantalum carbide crystals, J. Mater. Sci. 5 (1970) 345-350.

[2] A.S. Audion, P. Piantone, Panorama 2011 du marché du tantale, BRGM, rapport interne RP-61343-FR, 2012.

[3] C.F. Zalabak, The Melting Points of Tantalum Carbide and of Tungsten, Technical report No. NASA-TN-D-761, 1961.

[4] G. Santoro, H.B. Probst, An explanation of microstructures in the tantalumcarbon system, Adv. X-Ray Anal. 7 (1963) 126-135.

[5] E. Rudy, D.P. Harmon, Technical report No. AFML-TR-65-2, part I, Ternary Phase Equilibria in Transition Metal-boron-carbon-silicon Systems, vol. V, 1965.

[6] E.K. Storms, The Refractory Carbides, Academic Press, New York and London, 1967, pp. 82-93.

[7] W.F. Brizes, Diffusion of carbon in the carbides of tantalum, J. Nucl. Mater. 26 (1968) 227-231. 
[8] E. Fromm, U. Roy, The high-temperature solid solubility limit of carbon in tantalum, J. Less Common Met. 8 (1965) 73-75.

[9] B.H. Eckstein, R.F. Forman, Preparation and some properties of tantalum carbide, J. Appl. Phys. 33 (1962) 82-87.

[10] G. Hörz, K. Lindenmaier, The kinetics and mechanisms of the absorption of carbon by niobium and tantalum in a methane or acetylene stream, J. Less Common Met. 35 (1974) 85-95.

[11] G. Hörz, K. Lindenmaier, Carburization of refractory metals in hydrocarbons, in: 4. annual Spring Meeting of the Metallurgical Society of AIME, Boston, Massachusetts, USA, 8 May 1972, 1973, pp. 168-181.

[12] G. Santoro, Variation of some properties of tantalum carbide, Trans. Metall. Soc. AIME 227 (1963) 1361-1368.

[13] A. Tardif, J.M. Michel, J. Wach, Cinétique de décomposition du pentane sous $10^{-5} / 10^{-7}$ torr à la surface du tantale et des carbures $\mathrm{Ta}_{2} \mathrm{C}$ et $\mathrm{TaC}$, entre 1300 et 2300K, Surf. Sci. 26 (1971) 255-268.

[14] A. Raveh, A. Danon, J. Hayon, A. Rubinshtein, R. Shneck, J.E. Klemberg-Sapieha, L. Martinu, Characterisiation of carburized tantalum layers prepared in inductive RF plasma, Thin Solid Films, 392 (2001) 56-64.

[15] A. Rubinshtein, R. Shneck, A. Danon, J. Hayon, S. Nathan, A. Raveh, Surface treatment of tantalum to improve its corrosion resistance, Mater. Sci. Eng. A 302 (2001) 128-134.

[16] F.H. Ellinger, The tantalum - carbon system, Trans. Am. Soc. Met. 31 (1943) 89-104.

[17] R. Lesser, G. Brauer, Karbidphasen des Tantals, Z. für Met. 49 (1958) 622-626.

[18] E. Rudy, El Rudy, F. Benesovsky, Untersuchungen in system tantal-wolframkohlenstoff, Monatsh. für Chem. Verwandte Teile Anderer Wiss. 93 (1962) 1176-1195.

[19] R.V. Sara, C.E. Lowell, R.T. Dolloff, Research Study of Determine the Phase Equilibium Relations of Selected Metal Carbides at High Temperatures, Technical report No. WADDTR60-143, part IV, 1963.

[20] A.L. Bowman, The crystal structures of $\mathrm{V}_{2} \mathrm{C}$ and $\mathrm{Ta}_{2} \mathrm{C}$, Acta Crystallogr. 19 (1965) 6-9.

[21] A.I. Gusev, A.S. Kurlov, V.N. Lipatnikov, Atomic and vacancy ordering in carbide Zeta $\mathrm{Ta}_{4} \mathrm{C}_{3-\mathrm{X}}(0.28 \times 0.4)$ and phase equilibria in the Ta-C system, J. Solid State Chem. 180 (2007) 3234-3246.

[22] M. Rocher, P. Goeuriot, J. Dhers, Modelling of the growth of carbide layers in tantalum, Key Eng. Mater. 206-213 (2002) 527-530.

[23] R.A. Morris, B. Wang, L.E. Matson, G.B. Thompson, Microstructural formations and phase transformation pathways in hot isostatically pressed tantalum carbides, Acta Materalia, 60 (2012) 139-148.

[24] V.N. Lipatnikov, A.A. Rempel, Formation of the incommensurate ordered phase in $\mathrm{TaC}_{\mathrm{y}}$ carbide, J. Exp. Theor. Phys. 81 (2005) 326-330.

[25] A.I. Gusev, Sequence of phase transformations in the formation of superstructures of the $\mathrm{M}_{6} \mathrm{C}_{5}$ type in nonstoichiometric carbides, J. Exp. Theor. Phys. 109 (2009) 417-433.

[26] R. Resnick, R. Steinitz, L. Seigle, Determination of diffusivity of carbon in tantalum and columbium carbides by layer-growth measurement, Trans. Metall. Soc. AIME 233 (1965) 1915-1918.

[27] I. Zaplatynsky, Observations on zeta phase in the system Ta-C, J. Am. Ceram. Soc. 49 (1966) 109-110.
[28] E. Fromm, E. Gebhardt, U. Roy, Diffusion des Kohlenstoffs in den Karbidphasen des Tantals, Z. für Met. 57 (1966) 808-811.

[29] N.H. Krikorian, T.C. Wallace, R. Krohn, M.G. Bowman, Formation of Carbide Surfaces on Tantalum and Tantalum-tungsten Alloys, Los Alamos Nationa Laboratory, 1968. LA-AC-8803.

[30] H. Wiesenberger, W. Lengauer, P. Ettmayer, Reactive diffusion and phase equilibria in the V-C, Nb-C, Ta-C and Ta-N systems, Acta Materalia 46 (1998) $651-666$.

[31] W. Lengauer, Multiphase reaction diffusion in transition metal-carbon and transition metal-nitrogen systems, J. Alloys Compd. 229 (1995) 80-92.

[32] M. Rocher, Carburation d'un métal réfractaire et de ses alliages, Mécanismes et Modélisation, Ecole Nationale Supérieure des Mines de Saint Etienne, France, 2002. Thèse $\mathrm{N}^{\circ} 274 \mathrm{TD}$.

[33] M. Balooch, D.R. Olander, Reactions of modulated molecular beams with pyrolytic graphite. III. Hydrogen, J. Chem. Phys. 63 (1975) 4772-4786.

[34] E. Hoinkis, The chemisorption of hydrogen on porous graphites at low pressure and at elevated temperature, J. Nucl. Mater. 182 (1991) 93-106.

[35] R.A. Krakowski, D.R. Olander, Survey of the Literature on the Carbon-hydrogen System, Technical report LBNL UCRL-19149, 1970.

[36] D. Cotton, Etude de formation d'hémicarbure de tantale (Ta2C) par l'intermédiaire d'un procédé de cémentation sous pression réduite, PhD Thesis tel-01213990, Université de Bourgogne, 2015.

[37] M.M. Nowell, S.I. Wright, Orientation effects on indexing of electron backscatter diffraction patterns, Ultramicroscopy 103 (2005) 41-58.

[38] P. Vonlanthen, B. Grobety, CSL grain boundary distribution in alumina and zirconia ceramics, Ceram. Int. 34 (2008) 1459-1472.

[39] V.G. Zubkov, L.B. Dubrovskaya, P.V. Gel'd, V.A. Tskhai, Y.A. Dorofeev, Neutrondiffraction Study of the Ordering of Non Stoechiometric Cubic Carbides of Fifth-group Transition Metals, vol. 184, Doklady Akademii Nauk SSSR, 1968 pp. 874-876.

[40] V.N. Lipatnikov, A.I. Gusev, Atomic vacancy ordering in the carbide phase $\mathrm{Ta}_{4} \mathrm{C}_{3}$, Phys. Solid State 48 (2006) 1634-1645

[41] K. Yvon, E. Parthé, On the crystal chemistry of the close-packed transitionmetal carbides. I. The crystal structure of the zeta-V, Nb and Ta carbides, Acta Crystallogr. B 26 (1970) 149-153.

42] U. Dahmen, Microstructures and Phase Transformations in Interstitial Alloys of Tantalum, Lawrence Berkeley National Laboratory, 1979. LBNL Paper LBL8661.

[43] D.J. Rowcliffe, Structure of non-stoichiometric TaC, Mater. Sci. And Eng. A 18 (1975) 231-238.

44] X. Xiong, Z. Chen, B. Huang, G. Li, F, Zheng, P. Xiao, H. Zhang, Surface morphology and preferential orientation growth of TaC crystals formed by chemical vapor deposition, Thin Solid Films, 517 (2009) 3235-3239.

[45] T. Naiki, M. Ninomiya, M. Ihara, Epitaxial growth of tantalum carbide, Jpn. J. Appl. Phys. 11 (1972) 1106-1112.

[46] R.D. Vispute, S. Hullavarad, A. Luykx, D. Young, S. Dhar, T. Venkatesan, Epitaxy and recrystallization kinetics of $\mathrm{TaC}$ thin films on $\mathrm{SiC}$ for high temperature processing of semiconductor devices, Appl. Phys. Lett. 90 (2007), 24917 $1-24917-3$. 